\title{
Crystalline phase evolution in nanostructured copper sulfide thin films prepared by spray pyrolysis method: the effect of annealing
}

\author{
ROSHANAK RAFIEI NAZARI ${ }^{1, *}$, HODA ENAYATI TALOOBAGHI ${ }^{2}$, HOSEIN ESHGHI $^{2}$ \\ ${ }^{1}$ Department of Physics, South Tehran Branch, Islamic Azad University, Tehran, Iran \\ ${ }^{2}$ Physics Department, Shahrood University of Technology, Shahrood, 316-36155, Iran
}

\begin{abstract}
In this study, physical properties of copper sulfide thin films deposited on glass substrates by spray pyrolysis method at different temperatures $\left(260^{\circ} \mathrm{C}, 285^{\circ} \mathrm{C}\right.$ and $\left.310^{\circ} \mathrm{C}\right)$ were investigated. The influence of annealing time on the physical properties of grown layers was also studied. According to FESEM images, the sizes of the compact copper sulfide grains were varied from about $100 \mathrm{~nm}$ to $60 \mathrm{~nm}$. Hall effect and resistivity measurements confirmed that all samples had p-type conductivity. The XRD patterns showed that, together with the dominant digenite phase $\left(\mathrm{Cu}_{1.8} \mathrm{~S}\right)$ in all samples, the copper-rich phases also appeared as a result of increasing substrate temperature. The optical UV-Vis spectra analysis showed that due to increasing the substrate temperature, the band gap of the layers was reduced from about $2.4 \mathrm{eV}$ to $2.0 \mathrm{eV}$. We found that as a result of annealing at $400{ }^{\circ} \mathrm{C}$ for $1.5 \mathrm{~h}$ in $\mathrm{Ar}$ atmosphere, the sample which was initially grown at $310{ }^{\circ} \mathrm{C}$ with the highest copper content, totally transformed into the polycrystalline monoclinic chalcocite phase $\left(\mathrm{Cu}_{2} \mathrm{~S}\right)$ with 3D nanoporous architecture.
\end{abstract}

Keywords: porous copper sulfide; phase variation; nanostructures; spray pyrolysis; annealing process

\section{Introduction}

Thin layers of copper sulfide $\left(\mathrm{Cu}_{\mathrm{x}} \mathrm{S}, 1 \leqslant \mathrm{x} \leqslant 2\right)$, due to their special optical and electrical properties, have received much attention, as one of chalcogenide semiconductors, in many applications such as thermoelectric cooling materials [1], sunlightabsorbing layers [2-7], electro-conductive coatings [8] and chemical sensors [9]. These properties are often dependent on the type of structure and stoichiometry of the chemical composition. The copper-poor phase $(\mathrm{CuS})$ shows a metallic conductivity, and the copper-rich phase $\left(\mathrm{Cu}_{2} \mathrm{~S}\right)$ is typical of more resistive layers. For example, in $\mathrm{Cu}_{\mathrm{x}} \mathrm{S}$ compositions the resistivity of layers ranges from $10 \Omega \cdot \mathrm{cm}$ to $10^{-4} \Omega \cdot \mathrm{cm}$ for $\mathrm{x}=2$ to $\mathrm{x}=1$ [10]. Also a direct band gap of $1.25 \mathrm{eV}$ to $3.2 \mathrm{eV}$ has been reported for samples with different phases and compositions prepared by different techniques under different conditions $[2,11,12$, 14-16]. Thin layers of copper sulfide contain five

*E-mail: roshanrafiei@yahoo.com stable phases at room temperature including: covellite $(\mathrm{CuS})$, analite $\left(\mathrm{Cu}_{1.75} \mathrm{~S}\right)$, digenite $\left(\mathrm{Cu}_{1.8} \mathrm{~S}\right)$, djurleite $\left(\mathrm{Cu}_{1.95} \mathrm{~S}\right)$ and chalcocite $\left(\mathrm{Cu}_{2} \mathrm{~S}\right)$ [17-23]. The formation of each of these crystalline phases depends on different parameters such as deposition temperature, chemical composition of the materials, growth method, etc.

For the deposition of thin CuS layers, various physical and chemical methods, including chemical bath deposition (CBD) [2, 15, 24-26], vacuum evaporation [27], successive ionic layer adsorption and reaction (SILAR) $[18,28]$ and spray pyrolysis deposition [6, 11, 16, 29-32] have been used. These different methods mainly affect the morphology of copper sulfide samples. For example, samples with flower-like [18], nanowire [33] and star-like [34] morphologies have been prepared by various synthesis methods. Among those, most copper sulfide nanostructures prepared by spray pyrolysis technique have a relatively uniform surface with spherical nanoparticles $[6,11,16,30]$.

In this study, copper sulfide samples were deposited on glass substrates by spray pyrolysis 
technique at various temperatures. The effect of annealing time on the copper-rich sample was also investigated.

\section{Experimental}

To prepare thin layers of copper sulfide by spray pyrolysis technique, $100 \mathrm{~mL}$ aqueous solution containing $0.06 \mathrm{M}$ copper acetate $\mathrm{Cu}\left(\mathrm{CH}_{3} \mathrm{COO}\right)_{2} \cdot \mathrm{H}_{2} \mathrm{O}$ (99.9\% Merck) and $0.05 \mathrm{M}$ thiourea $\mathrm{CS}\left(\mathrm{NH}_{2}\right)_{2}$ ( $99.9 \%$ Merck) was prepared. The solution was deposited on glass substrates at different temperatures of $260{ }^{\circ} \mathrm{C}, 285^{\circ} \mathrm{C}$ and $310^{\circ} \mathrm{C}$ and the samples were designated as T1, T2 and T3, respectively. Before deposition, the substrates were cleaned with boiling distilled water and then degreased with acetone and ethanol solution in an ultrasonic device. Other deposition parameters including the pressure of the carrier gas, hot plate rotation speed and nozzle-tosubstrate distance, were fixed at: $250 \mathrm{kPa}, 30 \mathrm{rpm}$ and $33 \mathrm{~cm}$, respectively [11, 16, 31, 35].

The surface morphology of the samples was studied using a Mira 3-XMU field emission scanning electron microscopy (FESEM). For structural characterization of the samples X-ray diffraction (XRD) D8 Advance Bruker system with $\mathrm{CuK} \alpha$ radiation $\lambda=1.5405 \AA$ was used in the $2 \theta$ range of $10^{\circ}$ to $70^{\circ}$. To investigate the optical properties, the absorbance and transmittance spectra of the samples were recorded on a UV-Vis-Shimadzu1800 spectrophotometer in the wavelength range of $300 \mathrm{~nm}$ to $1100 \mathrm{~nm}$. Finally, the majority carrier type, their density and mobility, could be determined by Hall effect, in van der Pauw configuration, and resistivity measurements.

\section{Results and discussion}

\subsection{The effect of substrate temperature}

\subsubsection{Surface morphology}

Fig. 1 shows the FESEM images of samples prepared on glass substrates at different temperatures. As seen, the size of $\mathrm{CuS}$ grains in $\mathrm{T} 1$ is about $100 \mathrm{~nm}$. With increasing the substrate temperature, the grains were isolated and gradually tended to smaller porous grains of $80 \mathrm{~nm}$ and 60 $\mathrm{nm}$ on the surface of T2 and T3, respectively.

\subsubsection{Structural properties}

Fig. 2 shows the XRD patterns of the grown copper sulfide layers. As it is apparent, the sample prepared at substrate temperature of $260{ }^{\circ} \mathrm{C}$ T1 contains several phases with the dominant digenite phase $\left(\mathrm{Cu}_{1.8} \mathrm{~S}\right)$, (JCPDS Card No. 23-0962) together with the copper-poor phase, CuS (JCPDS Card No. 03-0724). With increasing the substrate temperature this extra phase in $\mathrm{T} 2$ is disappearing and the layer has only digenite phase with the preferred orientation along ( $\left.\begin{array}{lll}1 & 1 & 0\end{array}\right)$. Interestingly, with increasing the substrate temperature up to $310{ }^{\circ} \mathrm{C} \mathrm{T} 3$, in addition to the digenite phase, again an extra copper-rich djurleite phase $\left(\mathrm{Cu}_{1.96} \mathrm{~S}\right)$ has appeared.

According to these data, with increasing the substrate temperature the copper-rich phase appears. Due to the fact that the digenite phase is the dominant phase in all three samples and the peak related to $\left(\begin{array}{lll}1 & 1 & 0\end{array}\right)$ plane could be considered as the preferred direction, the corresponding data were used to calculate the average crystallite size D, using Scherrer formula [9, 36, 37]:

$$
D=\frac{0.9 \lambda}{\beta \cos \theta}
$$

where $\lambda$ is the wavelength of the X-ray beam, $\beta$ is the full width at half-maximum (FWHM, in radians) and $\theta$ is the Bragg angle of the diffraction peak. Also the dislocation density and the induced crystal strain of the samples were calculated using equation 2 and equation 3 , respectively $[38,39]$ :

$$
\delta=\frac{1}{D^{2}}
$$

$$
\varepsilon=\frac{\beta}{4 \tan \theta}
$$

The final results are shown in Table 1 .

\subsubsection{Electrical properties}

To evaluate the majority carrier type, the density and mobility, Hall effect and resistivity 


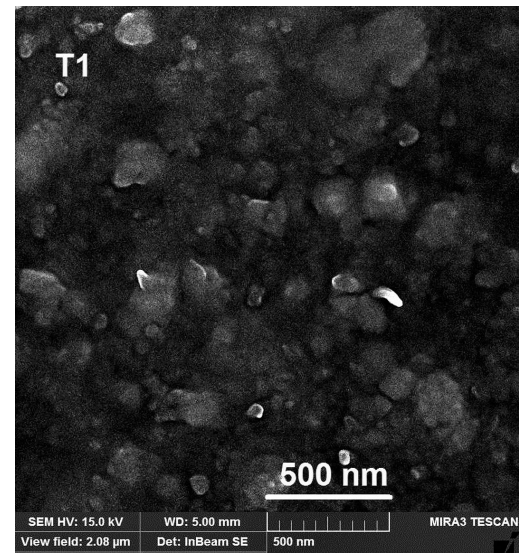

(a)

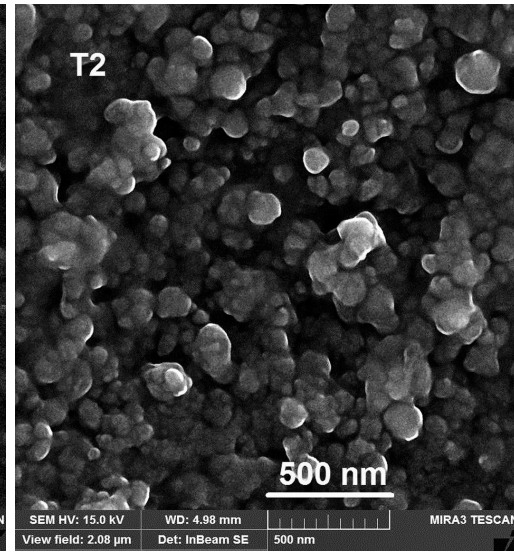

(b)

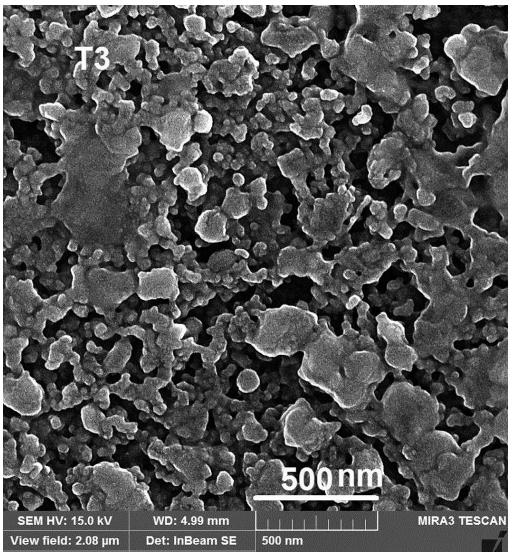

(c)

Fig. 1. The FESEM images of the samples prepared at different substrate temperatures (a) $260{ }^{\circ} \mathrm{C}$, (b) $285^{\circ} \mathrm{C}$ and (c) $310{ }^{\circ} \mathrm{C}$.

Table 1. Average crystallite size, induced crystal strain, dislocation density and direct band gap in the studied samples.

\begin{tabular}{lcccc}
\hline \multicolumn{1}{c}{ Sample } & $\mathrm{D}[\mathrm{nm}]$ & $\epsilon\left(10^{-3}\right)$ & $\delta \times 10^{-4}\left[\mathrm{~nm}^{-2}\right]$ & $\mathrm{E}_{\mathrm{g}}[\mathrm{eV}]$ \\
\hline \hline T1 & 18.75 & 6.6 & 28.44 & 2.41 \\
T2 & 17.72 & 6.2 & 31.84 & 2.30 \\
T3 & 11.37 & 9.0 & 77.35 & 2.01 \\
T3a-1.0 & 21.83 & 5.3 & 20.98 & 1.94 \\
T3a-1.5 & 24.07 & 4.9 & 17.26 & 1.23 \\
\hline
\end{tabular}

measurements were carried out at room temperature. Majority carrier concentration $\left(\mathrm{N}_{\mathrm{n}, \mathrm{p}}\right)$ was obtained using equation [40]:

$$
N_{n, p}=\frac{I B}{|q| V_{H} d}
$$

where $\mathrm{I}, \mathrm{B}, \mathrm{q}, \mathrm{V}_{\mathrm{H}}$ and $\mathrm{d}$ are the current, magnetic field $=300 \mathrm{mT}$, electron charge, Hall voltage and film thickness, respectively. The sign of Hall voltage indicates the type of majority carriers, + for holes and - for electrons. Our measurements showed all samples had p-type conductivity, which was in good agreement with other reports $[9,10,41]$. According to the literature reports, the origin of this conductivity in pure copper sulfide layers is mainly due to the presence of copper vacancies $\mathrm{V}_{\mathrm{Cu}}$ in the crystal lattice, acting as acceptor-like states in the band gap of the material [6, 42]. Fig. 3 shows the evaluated hole density $\mathrm{p}$, hole mobility $\mu$ and resistivity $\rho$ of the samples. According to these data, although the carrier mobility has not significantly changed (in the range of $40 \mathrm{~cm}^{2} / \mathrm{V} \cdot \mathrm{s}$ to $100 \mathrm{~cm}^{2} / \mathrm{V} \cdot \mathrm{s}$ ), the hole density, especially in T3 decreased significantly and changed from $\sim 1 \times 10^{21} \mathrm{~cm}^{-3}$ in $\mathrm{T} 1$ and T2, to about $3 \times 10^{18} \mathrm{~cm}^{-3}$ in T3 (almost three orders of magnitude lower). This huge change in carrier density can be due to the increment of copper atoms in the crystal lattice of this sample T3 leading to the formation of djurleite phase $\left(\mathrm{Cu}_{1.96} \mathrm{~S}\right)$, as compared to other two samples.

\subsubsection{Optical properties}

Fig. 4 shows the transmittance and absorbance spectra of the samples, respectively. As seen, the transmittance spectra follow a Gaussian-like shape with maximum values of about $5 \%$ to $6 \%$, which could be due to the presence of porosity [43] in the grown samples, shown in Fig. 1. In addition, 


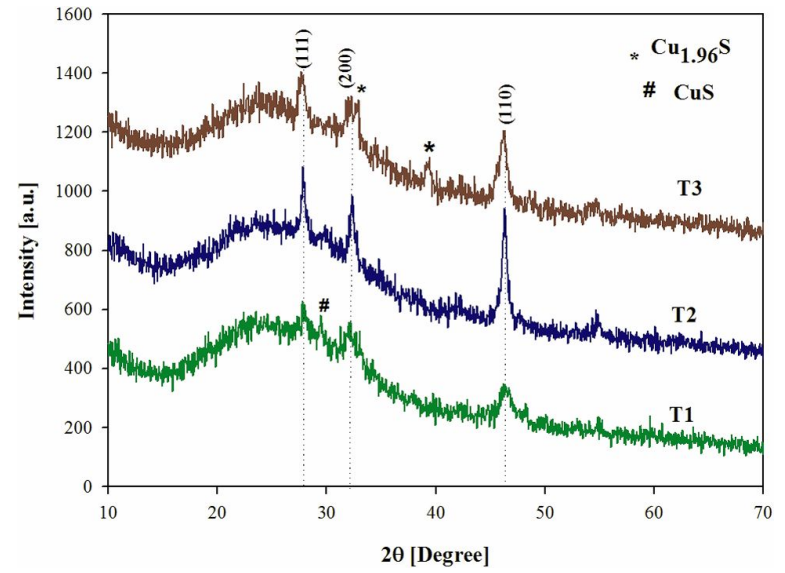

Fig. 2. The $\mathrm{X}$-ray spectra of the studied thin films with the dominant digenite phase $\left(\mathrm{Cu}_{1.8} \mathrm{~S}\right)$. As it is shown extra phases appear at different substrate temperatures.

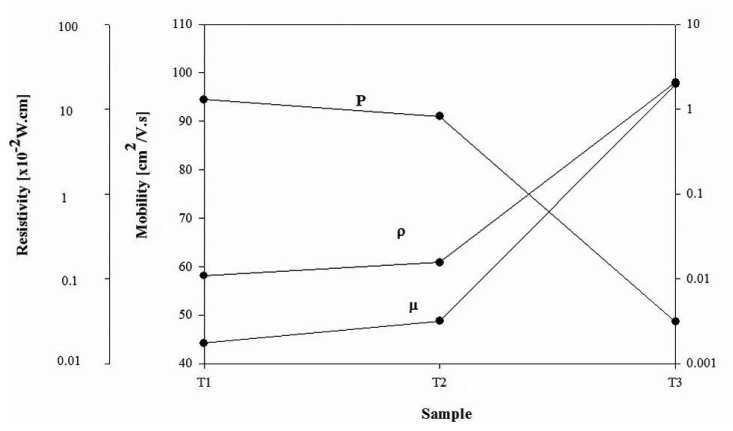

Fig. 3. The variations of resistivity $\rho$, hole density $\mathrm{p}$ and hole mobility $\mu$ in the samples.

the low transmittance of the samples could be attributed to the relatively high thickness (about $300 \mathrm{~nm}$ ), small crystallite size and high crystalline strain of the layers (Table 1). All these factors may tend to increase the scattering of the photons within the deposited films. In addition, two falling trends are also present in the transmittance spectra of the layers. As expected, reduction in the transmittance spectra in short wavelengths region (high photon energies) could be mainly influenced by the absorption of photons due to electronhole excitation between the levels within the band gap and/or the inter-band excitations. On the other hand, reduction in the transmittance spectra in long wavelengths region (low photon energies) could be related to the free carrier absorption and the occurrence of plasma oscillations. According to the relevant theory, with decreasing the carrier density the characteristic quantity of this phenomenon, i.e. the plasma wavelength $\lambda_{\mathrm{p}}$ extends towards longer wavelengths. This is clearly evident in the transmittance spectrum of T3. These results are also consistent with incremental variations in the absorbance spectra in long and short wavelengths regions, as shown in Fig. $4 \mathrm{~b}$.

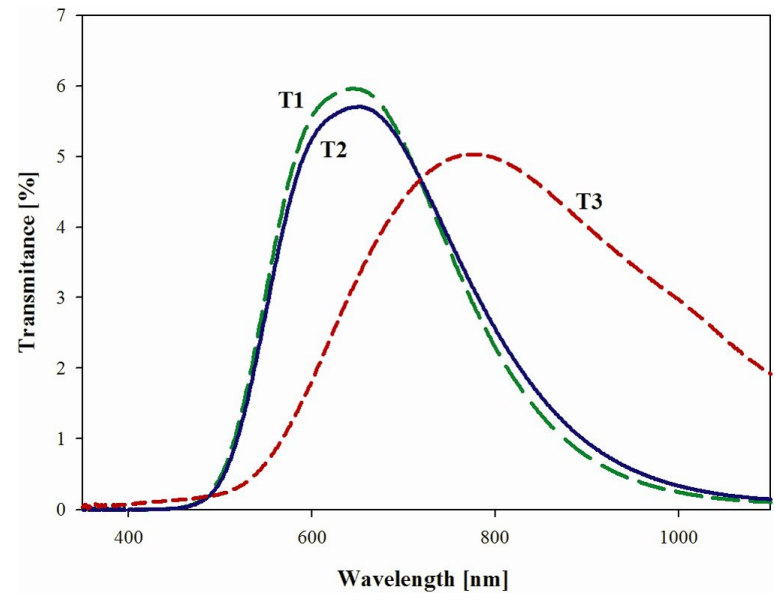

(a)

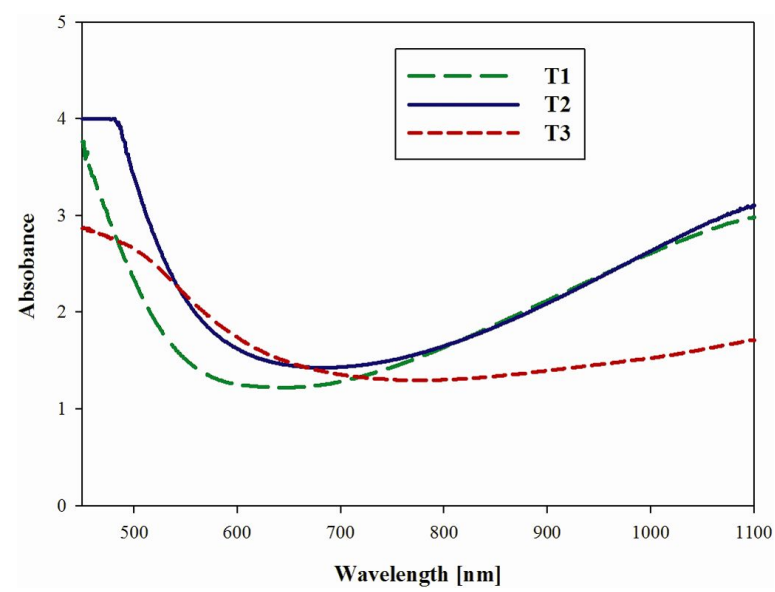

(b)

Fig. 4. The optical (a) transmittance and (b) absorbance spectra obtained from the as-deposited samples.

The direct band gap $\mathrm{E}_{\mathrm{g}}$ of the samples can be calculated using the absorbance (Fig. 4b) spectra of the layers and the Beer-Lambert theory [6]:

$$
(a h v)^{2}=A\left(h v-E_{g}\right)
$$


where $\mathrm{A}$ is a constant. It can be found by plotting $(\mathrm{ah} v)^{2}$ versus $\mathrm{h} v$ and extrapolating the straight portion to the energy axis, i.e. $(\mathrm{ah} v)^{2}=0$, (Fig. 5). As seen, with increasing the substrate temperature, the band gap of the sample $\mathrm{T} 1$ decreases from $2.41 \mathrm{eV}$ to $2.30 \mathrm{eV}$ in $\mathrm{T} 2$, and finally to $2.01 \mathrm{eV}$ in $\mathrm{T} 3$. The reduction in the band gap can be due to the formation of new crystalline phases in these layers, as confirmed by the XRD patterns. According to the literature reports $[2,28]$, the direct band gap of copper sulfide in its copper-rich phases $\left(\mathrm{Cu}_{1.8-2} \mathrm{~S}\right)$ is smaller than in its copper-poor phases $\left(\mathrm{Cu}_{1-1.8} \mathrm{~S}\right)$ that is consistent with our results.

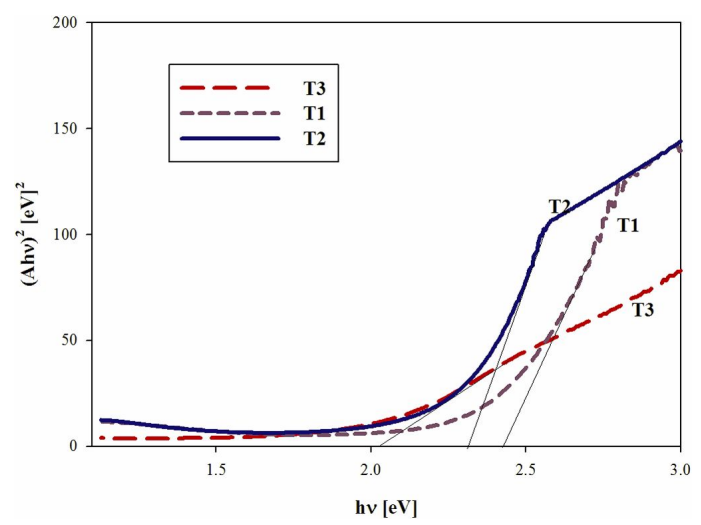

Fig. 5. Estimation of direct band gap of the samples $\mathrm{T} 1, \mathrm{~T} 2$ and $\mathrm{T} 3$ based on absorption spectra and equation 5 .

\subsection{The effect of annealing time copper-rich copper sulfide sample}

Considering the formation and appearance of new crystalline phases with increasing substrate temperature, the effect of annealing on T3 sample, containing copper-rich phase $\left(\mathrm{Cu}_{1.9} \mathrm{~S}\right)$, was chosen to provide favorable conditions to improve its physical properties towards higher copper-rich phases, i.e. $\mathrm{Cu}_{2} \mathrm{~S}$. For this purpose, the sample was annealed at $400{ }^{\circ} \mathrm{C}$ in the presence of argon flow in two conditions: $1 \mathrm{~h}$ (T3-a1.0) and 1.5 h (T3-a1.5) and the physical properties of these samples have been studied.

\subsubsection{Surface morphology}

Fig. 6 shows the surface morphology of T3, before and after annealing. Clearly, with increasing annealing time the surface grains became finer and their sizes were reduced from about $50 \mathrm{~nm}$ to $30 \mathrm{~nm}$ and the porosity increased as the annealing time was increased from $1 \mathrm{~h}$ to $1.5 \mathrm{~h}$. Such a porous nanostructure is highly attractive in designing gas sensors [9, 44] or catalysis [45] because porous structure is clearly far more favorable for the diffusion of gas molecules in gas sensors. On the other hand, the high porosity improves the catalytic performance of the nanostructure because of rapid diffusion of reactants and better accessibility of the reactants to the active sites.

\subsubsection{Structural properties}

Fig. 7 shows the effect of annealing on the XRD pattern of sample T3. As seen, the crystallinity of the digenite phase in $\mathrm{T} 3-\mathrm{a} 1.0\left(\mathrm{Cu}_{1.8} \mathrm{~S}\right)$ was improved and some peaks related to the djurleite phase $\left(\mathrm{Cu}_{1.96} \mathrm{~S}\right)$ started to appear. Interestingly, these changes continued with increasing the annealing time to $1.5 \mathrm{~h}$ (sample T3-a1.5) so that the digenite and djurleite phases were completely removed and only the single-phase monoclinic polycrystalline chalcocite $\left(\mathrm{Cu}_{2} \mathrm{~S}\right.$, JCPDS Card No. 33-0490) has appeared. With regards to the increasing porosity of the samples (Fig. 6), it seems that copper-rich phase $\left(\mathrm{Cu}_{2} \mathrm{~S}\right)$ appeared due to the evaporation of sulfur in sample T3-a1.5, which is in good agreement with the results of XRD patterns.

The average size of crystallites in the annealed samples was calculated using the Scherrer formula (Table 1), and the results show their sizes increased. The changes in the crystallite size with increasing the copper-rich phase in the sample can affect the electrical and optical properties of the layer as it is discussed in the following section.

\subsubsection{Electrical properties}

The effects of annealing time on the electrical properties of the samples were evaluated by Hall effect and resistivity measurements. Fig. 8 shows hole density, hole mobility and resistivity of the samples before and after annealing. As expected, with increasing the average crystallite size after annealing the hole mobility has increased (about 1.5 times and 2 times, respectively). 


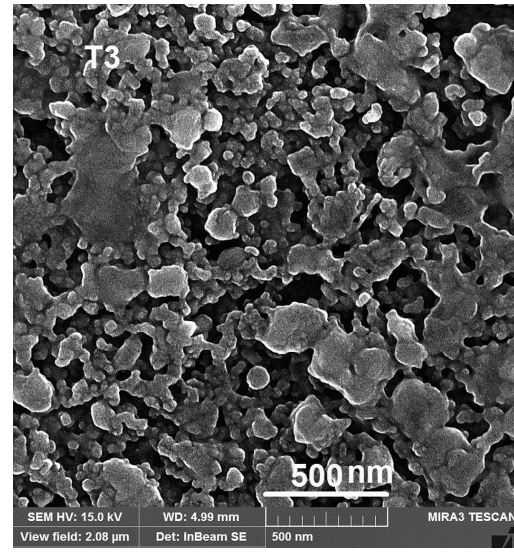

(a)

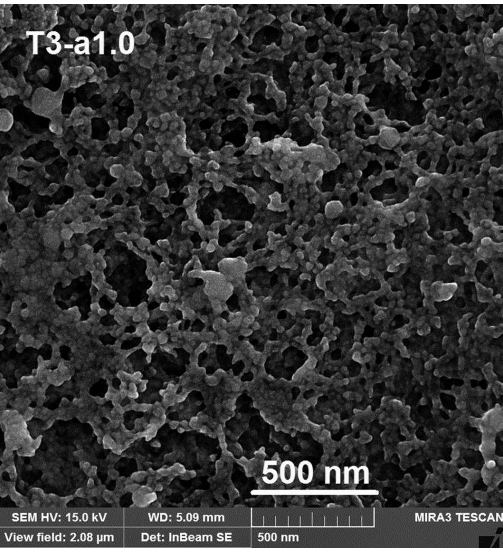

(b)

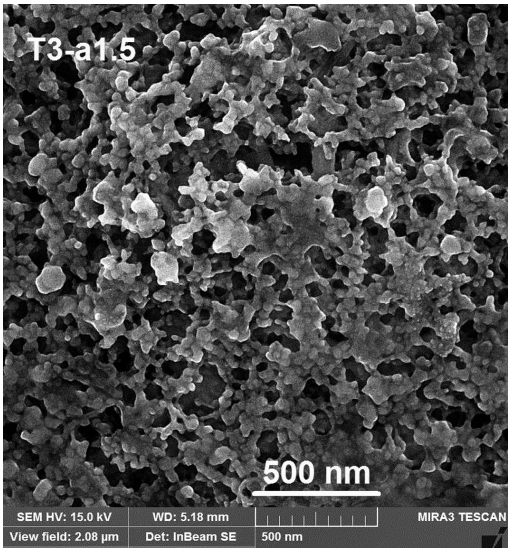

(c)

Fig. 6. The surface morphology of T3 (a) before annealing, after annealing (b) for $1 \mathrm{~h}$ and (c) $1.5 \mathrm{~h}$.

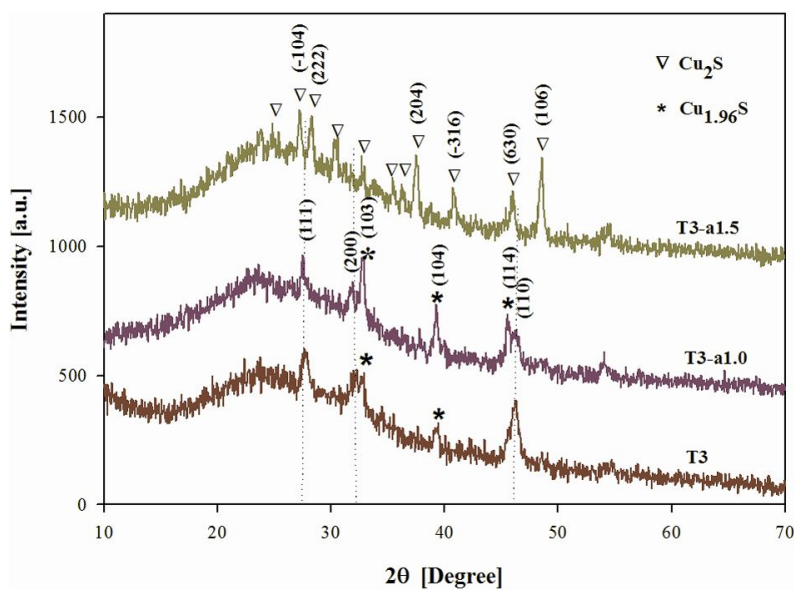

Fig. 7. The XRD patterns of sample T3, before and after annealing for $1 \mathrm{~h}$ and $1.5 \mathrm{~h}$.

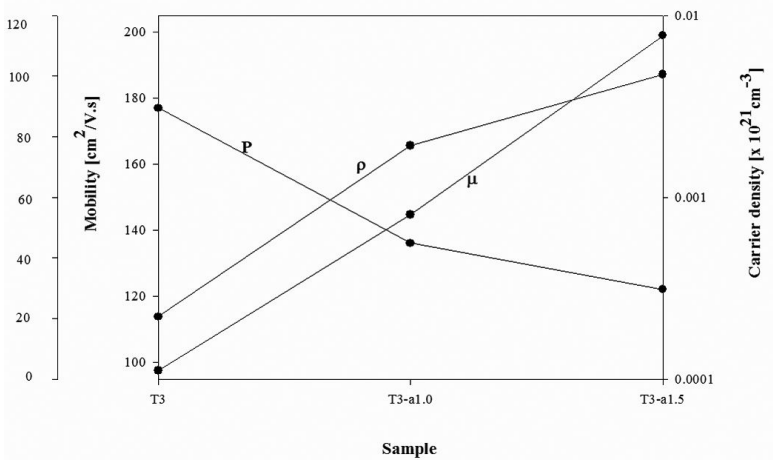

Fig. 8. The variations in electrical resistance, hole density and mobility in T3 before and after annealing for $1 \mathrm{~h}$ and $1.5 \mathrm{~h}$.
Meanwhile, with increasing the copper-rich phase in the annealed samples the hole density has decreased from $\sim 3 \times 10^{18} \mathrm{~cm}^{-3}$ in T3 to $\sim 6 \times 10^{17} \mathrm{~cm}^{-3}$ in T3-a1.0 and then to $\sim 4 \times 10^{17} \mathrm{~cm}^{-3}$ in $\mathrm{T} 3-\mathrm{a} 1.5$ sample.

These results are consistent with gradual decrease in the density of acceptor-like states originating from $\mathrm{V}_{\mathrm{Cu}}$ in the lattice, tending towards the growth of copper rich layers, i.e. $\mathrm{Cu}_{2} \mathrm{~S}$ phase.

\subsubsection{Optical properties}

Fig. 9 shows the transmission and absorbance spectra of T3 before and after annealing. As seen, with decreasing the hole density of the annealed samples, light absorption by free carriers in the long wavelength region has decreased and thus transmission through the layers has increased, which is a confirmation for the free carrier absorption by plasma oscillation effect.

The band gap of each annealed sample was also calculated using equation 5. The results are shown in Fig. 10. As shown, the direct band gap of the sample decreased from $2.01 \mathrm{eV}$ to $1.94 \mathrm{eV}$ and then to $1.23 \mathrm{eV}$ with increasing the annealing time. The value obtained for the sample T3-a1.5 is consistent with the results of other researchers who reported the band gap of $1.25 \mathrm{eV}$ to $2.53 \mathrm{eV}$ for chalcocite copper sulfide [13, 18, 25]. 


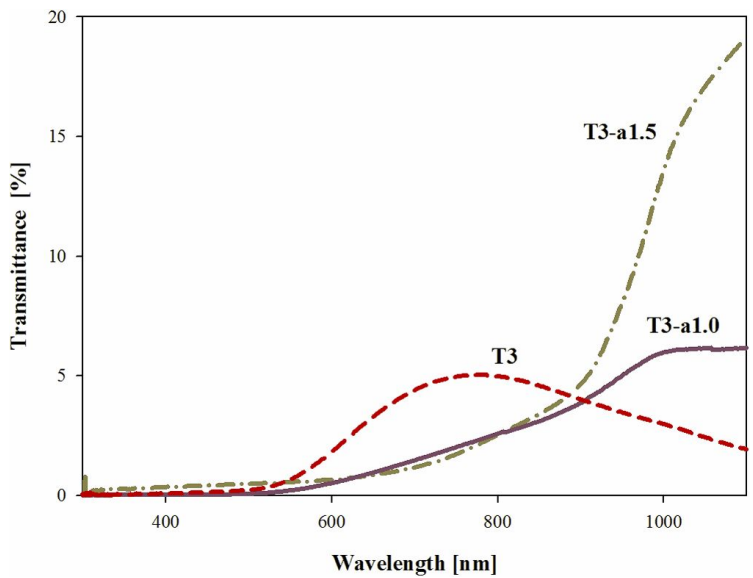

(a)

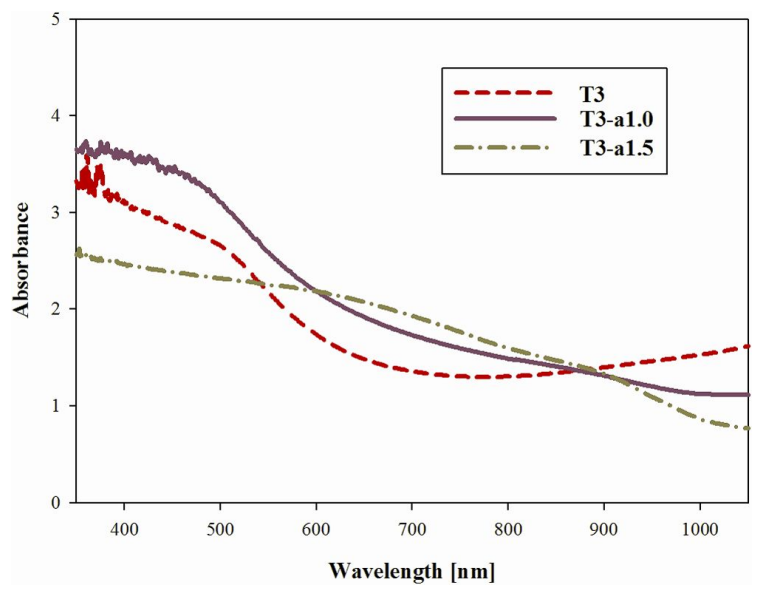

(b)

Fig. 9. The optical (a) transmittance and (b) absorbance spectra of $\mathrm{T} 3$ before and after annealing for $1 \mathrm{~h}$ and $1.5 \mathrm{~h}$.

\section{Conclusions}

In this research, nanostructures of thin layers of copper sulfide $\left(\mathrm{Cu}_{\mathrm{x}} \mathrm{S}, \mathrm{x}=1\right.$ to 2$)$ were deposited on glass substrates by spray pyrolysis technique at various substrate temperatures of $260{ }^{\circ} \mathrm{C}, 285^{\circ} \mathrm{C}$ and $310{ }^{\circ} \mathrm{C}$ and their conversion to copper-rich phases $\left(\mathrm{Cu}_{1.96} \mathrm{~S}\right.$ and $\left.\mathrm{Cu}_{2} \mathrm{~S}\right)$ by annealing in an argon atmosphere was studied. The surface morphology of the layers indicated that with increasing the substrate temperature, the grain sizes became finer and gradually changed from $100 \mathrm{~nm}$ to less than $50 \mathrm{~nm}$. X-ray diffraction patterns of the samples indicated the formation of the dominant digenite phase. We found that samples tended to grow with

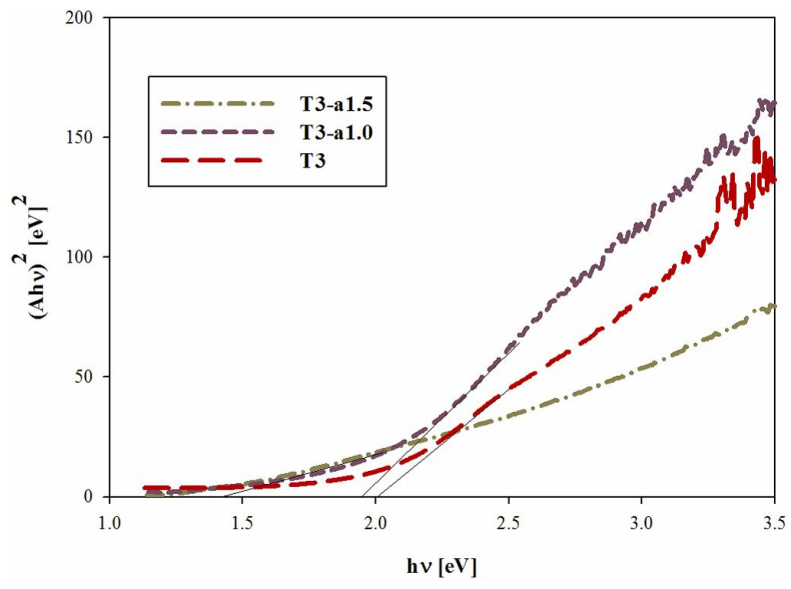

Fig. 10. Estimation of band gap of the samples T3, T3-a1.0 and T3-a1.5 based on absorption spectra and equation 5 .

the copper-rich djurleite phase together with a significant reduction in the hole density (about 3 orders of magnitude) by increasing the growth temperature. In addition, the band gap was decreased from $\sim 2.4 \mathrm{eV}$ to $2 \mathrm{eV}$. Annealing the sample grown at $310{ }^{\circ} \mathrm{C}$ at the temperature of $400{ }^{\circ} \mathrm{C}$ for $1.5 \mathrm{~h}$, transformed it into polycrystalline monoclinic chalcocite $\left(\mathrm{Cu}_{2} \mathrm{~S}\right)$ phase and increased the sample porosity.

\section{Acknowledgements}

Financial support of this research, in a project No.: B/16/922; entitled: Study on physical properties of copper sulfide thin films, from the Islamic Azad University, South Tehran Branch, is acknowledged.

\section{References}

[1] Shen X.P., Zhao H., Shu H.Q., Zhou H., Yuan A.H., J. Phys. Chem. Solids 70 (2009), 422.

[2] Nair M., Guerrero L., NAIR P., Semicond. Sci. Tech. 13 (1998), 1164.

[3] Ezenwa I.A., Res. J. Eng. Sci., 2 (2013), 1.

[4] Anuar K., Zainal Z., Hussein M., Saravanan N., Haslina I., Sol. Energ. Mat. Sol. C., 73 (2002), 351.

[5] Cuevas A., Romero R., Leinen D., Dalchiele E., Ramos-Barrado J., Martin F., Sol. Energ. Mat. Sol. C., 134 (2015), 199.

[6] IsaC L., Duta A., Kriza A., Manolache S., NANU M., Thin Solid Films, 515 (2007), 5755.

[7] Taur V.S., Joshi R. A., Ghule A.V., Sharma R., Renew. Energ., 38 (2012), 219.

[8] Lindroos S., Arnold A., Leskelä M., Appl. Surf. Sci., 158 (2000), 75. 
[9] Sagade A.A., Sharma R., Sensor. Actuat. BChem.,133 (2008), 135.

[10] Bollero A., Grossberg M., Asenjo B., GutiérREZ M., Surf. Coat. Tech., 204 (2009), 593.

[11] Kim W.Y., Palve B.M., Pathan H.M., Joo O.S., Mater. Chem. Phys., 131 (2011), 525.

[12] Isac L., Duta A., Kriza A., NAnu M., SchoonMAN J., J. Optoelectron. Adv. M., 9 (2007), 1265.

[13] Podder J., Kobayashi R., Ichimura M., Thin Solid Films, 472 (2005), 71.

[14] Xin M., Li K., Wang H., Appl. Surf. Sci., 256 (2009), 1436.

[15] Yildirim M.A., Ateş A., Astam A., Physica E, 41 (2009), 1365.

[16] Is ac L., Popovici I., Enesca A., Duta A., Energy Procedia, 2 (2010), 71.

[17] Li S., Wang H., Xu W., Si H., Tao X., Lou S., Du Z., LI L.S., J. Colloid Interf. Sci., 330 (2009), 483.

[18] Peng M., Ma L.L., Zhang Y.G., Tan M., Wang J.B., YU Y., Mater. Res. Bull., 44 (2009), 1834.

[19] PopovicI I., Is AC L., DUŢă A., Bulletin of the Transilvania University of Braşov, 2 (2009), 51.

[20] Lenggoro I.W., Kang Y.C., KomiYA T., Okuyama K., Tohge N., Jpn. J. Appl. Phys., 37 (1998), L288.

[21] Rhee J.H., LeE Y.H., Bera P., SeOK S.I., Chem. Phys. Lett., 477 (2009), 345.

[22] Tezuka K., Sheets W.C., Kurihara R., Shan Y.J., Imoto H., Marks T.J., Poeppelmeier K.R., Solid State Sci., 9 (2007), 95.

[23] Putnis A., Am. Mineral., 62 (1977), 107.

[24] Puspitasari I., Gujar T., Jung K.D., Joo O.S., Mater. Sci. Eng. B-Adv., 140 (2007), 199.

[25] Mukherjee N., Sinha A., Khan G.G., ChanDRA D., Bhaumik A., Mondal A., Mater. Res. Bull., 46 (2011), 6.

[26] Krylova V., Mater. Sci.-Poland, 25 (2007), 933.

[27] Reijnen L., Meester B., Delange F., SchoonMAN J., Goossens A., Chem. Mater., 17 (2005), 2724.

[28] LiN M.C., LEE M.W., Electrochem. Commun., 13 (2011), 1376.
[29] Bombicz P., Mutikainen I., Krunks M., Leskelä T., MadARÁsz J., NiInistö L., Inorg. Chim. Acta, 357 (2004), 513.

[30] Wang S.Y., Wang W., Lu Z.H., Mater. Sci. Eng., BAdv., 103 (2003), 184.

[31] Madarász J., OKuya M., Kaneko S., J. Eur. Ceram. Soc., 21 (2001), 2113.

[32] Naşcu C., Pop I., Ionescu V., Indrea E., BRATU I., Mater. Lett., 32 (1997), 73.

[33] Xu J., Cui X., Zhang J., Liang H., Wang H., Li J., B. Mater. Sci., 31 (2008), 189.

[34] Zou J., Zhang J., Zhang B., ZhaO P., HuAng K., Mater. Lett., 61 (2007), 5029.

[35] Patil P.S., Mater. Chem. Phys., 59 (1999), 185.

[36] Sahal M., Marí B., Mollar M., Thin Solid Films, 517 (2009), 2202.

[37] Rao T.P., Santhoshkumar M., Appl. Surf. Sci., 255 (2009), 7212.

[38] Caglar M., Ilican S., Caglar Y., Opt. Commun., 281 (2008), 1615.

[39] Sahay P., Nath R., Sensor. Actuat. B-Chem., 134 (2008), 654.

[40] Bagheri-Mohagheghi M.M., ShahtahMASEbi N., Alinejad M.R., Youssefi A., ShoKooh-SARemi M., Solid State Sci., 11 (2009), 233.

[41] Yuan K., Wu J., LiU M., Zhang L., XU F., Chen L., Huang F., Appl.Phys.Lett., 93 (2008), 132106.

[42] Grozdanov I., NAJdoski M., J. Solid State Chem., 114 (1995), 469.

[43] LiU Z., Li J., YA J., XIN Y., Jin Z., Mater. Lett., 62 (2008), 1190.

[44] Shinde M.S., Patil D., Patil R., Indian J. Pure Ap. Phy.,51(2013), 713.

[45] An L., Zhou P., Yin J., Liu H., Chen F., LiU H., DU Y., XI P., Inorg. Chem., 54 (2015), 3281.

Received 2017-05-23 Accepted 2017-09-22 